\title{
Verbal Assistance within the Context of an IADL Evaluation
}

\author{
Guylaine Le Dorze1,2*, Judith Villeneuve ${ }^{1,2}$, Anna Zumbansen ${ }^{1,2}$, \\ Michèle Masson-Trottier ${ }^{1,2}$, Carolina Bottari ${ }^{2,3}$ \\ ${ }^{1}$ School of Speech-Language Therapy and Audiology, Faculty of Medicine, Université de Montréal, Montreal, \\ Canada \\ ${ }^{2}$ Centre for Interdisciplinary Research in Rehabilitation of Greater Montreal, Montreal, Canada \\ ${ }^{3}$ Occupational Therapy Program, School of Rehabilitation, Faculty of Medicine, Université de Montréal, \\ Montreal, Canada \\ Email: "guylaine.le.dorze@umontreal.ca
}

Received 19 August 2014; revised 20 September 2014; accepted 18 October 2014

Academic Editor: Silvio Mario Meloni, MS Oral Surgeon, University of Sassari, Italy

Copyright (C) 2014 by authors and Scientific Research Publishing Inc.

This work is licensed under the Creative Commons Attribution International License (CC BY).

http://creativecommons.org/licenses/by/4.0/

(c) (i) Open Access

\begin{abstract}
Objective: The aim of this study was to identify the types of verbal assistance that facilitate task progression in individuals with cognitive deficits secondary to traumatic brain injury (TBI). Methods: Two individuals with moderate-to-severe TBI needing verbal assistance to complete the "Obtaining Information task" of the Instrumental Activities of Daily Living Profile were selected. A qualitative conversational analysis was conducted on the complete verbatim of the interactions that occurred between the evaluator and each participant while planning how they would find the information. The evaluator provided the least possible assistance to observe the maximal levels of independence of each individual. Results and Outcomes: Six types of verbal assistance, offered in response to each participant's specific problems, facilitated goal formulation for finding information: restarting, scaffolding, cueing, action priming, offer of a strategy, and explicit advice. Explicit advice that involved the therapist thinking for the person was only provided after numerous other types of more implicit assistance had failed to facilitate task progression. Conclusions: Therapists can facilitate task-related goal formulation and attainment in individuals with cognitive limitations using several types of well-adjusted verbal assistance.
\end{abstract}

\section{Keywords}

Traumatic Brain Injury, Verbal Assistance, Qualitative Analysis, IADL

\footnotetext{
${ }^{*}$ Corresponding author.
} 


\section{Introduction}

People with moderate or severe traumatic brain injury (TBI) are likely to present cognitive disorders affecting executive functions that reduce their independence in instrumental activities of daily living (IADL) and social participation [1] [2]. The offer of verbal assistance by clinicians is sometimes critical in facilitating the performance of these individuals in everyday tasks. Verbal assistance is in fact an element of several functional rating scales and of central importance to eventual clinical recommendations for individuals with cognitive limitations [3]. However, little attention has been given to understanding what constitutes verbal assistance within the context of these evaluations, how verbal assistance can support functional performance and what type of verbal assistance benefits performance. This study aimed to define and characterize verbal assistance as it is provided in context and to explore how the offer of verbal assistance is linked to particular cognitive limitations and how it actually helps.

Verbal assistance provided within the context of IADL evaluations is offered to help with a broad variety of problems to which the individual with cognitive limitations can potentially be faced in the context of everyday situations. Verbal assistance can be offered to identify the steps involved in a task, to direct the individual's attention to the task, to provide rhythm to the execution of a task and to facilitate the pursuit of a task [4]. However, how and when verbal assistance should be provided is rarely specified in IADL evaluation guidelines. Moreover, it is unclear what constitutes verbal assistance, whether these are general encouragement, or specific bits of information, or questions that should be posed to the patient. Thus the lack of an explicit understanding of this concept creates a problem for its use.

It is believed that verbal assistance should be given in a hierarchical fashion; yet to apply this suggestion one has to rely on clinical judgment rather than on clear indications of when and how assistance should be provided [5]. To grasp the concept of verbal assistance, the contexts or situations within which it is used need to be examined. Moreover, given that individuals with moderate to severe TBI usually experience some degree of communication impairment, referred to as "cognitive - communication" or "cognitive - linguistic" disorders [6], the beneficial effect of verbal "assistance" under some circumstances may be misjudged. The extent to which verbal assistance is beneficial for the individual with a TBI is in fact not usually considered [5].

More attention needs to be paid to the interaction between the individual and the examiner. Evidence suggests that conversational partners of people with TBI play a significant role in interactions and can limit the success of an interaction when the verbal "support" is inadequate [7] [8]. When the verbal support or assistance is adequate, the interaction can be enhanced such that the individual's difficulties are attenuated [9] [10]. Therefore it seems crucial to study verbal assistance as it is provided to individuals with TBI within the natural interaction that arises within an evaluation session. Given that verbal assistance is intended to help an individual perform, it seemed pertinent to examine how and the extent to which "assistance" effectively enhances performance.

To the best of our knowledge no study has yet examined the functioning of individuals with TBI in interaction with an occupational therapist within an IADL evaluation session. In the absence of previous work, we turned to conversational analysis, a qualitative research approach to explore the talk generated within the evaluation session, because of the demonstrated value of such an approach in the study of other types of patient-health provider interactions, i.e., speech-language pathology. See Simons-Mackie and Damico [11] [12] and Horton [13] for examples. The aim of this investigation was to identify the types of verbal assistance that facilitate task progression in individuals with cognitive limitations secondary to traumatic brain injury (TBI), within the context of an IADL evaluation administered by an expert occupational therapist.

\section{Methods}

\subsection{Participants}

The examiner was a female OT with 20 years of experience with a TBI population, who had tested over 60 individuals with moderate to severe TBI using the IADL Profile [3] (see below for tool description) and largely contributed to the development of the tool.

Over 100 consenting individuals with TBI were tested with the IADL Profile within the context of a study of its psychometric qualities over a period of 2 years [1] [3] [14]. These participants were a convenience sample recruited from 12 rehabilitation hospitals in Quebec, Canada. Subjects were between the ages of 18 and 65, had sustained a moderate or severe TBI and were proficient in French. For the purpose of the present study, the "Obtaining Information" task of the IADL Profile was selected because it was found to be of a high level of dif- 
ficulty for many individuals with TBI. Several video recordings of the task were viewed with the idea of selecting participants for whom multiple instances of assistance had been required to facilitate task progression. This study was approved by the research ethics committee of the Centre for Interdisciplinary Research in Rehabilitation.

Seven participants' recordings of the "Obtaining Information" task were transcribed and analysed in depth as described below. For the purpose of the present study, two participants were chosen because both required extensive assistance. Both experienced difficulties in executive function that had repercussions on their independence in everyday activities, yet had different cognitive profiles.

\section{Participant TN}

TN was a 59-year-old man who sustained a severe TBI subsequent to a car accident 18 months prior to our evaluation. His Glasgow Coma Scale score at emergency was 5/15. He remained in a comatose state for 26 days and post-traumatic amnesia lasted for 34 days. Neuropsychological testing at discharge from post-acute rehabilitation revealed a frontal syndrome with disinhibition and perseveration. Test results also suggested anosognosia, decreased judgment, reduced tolerance to cognitive effort, fatigue, decreased working memory and decreased verbal and visual learning ability. An audiology report also suggested the presence of a slight neurosensory hypoacousia. Following rehabilitation, he returned home to live with his wife and adult son. At the time of testing, he reported that he had been unable to think for the first two months post-injury. However, he now felt able to think and plan things. He reported having an approximate of 30-minute tolerance of cognitive effort and often forgetting what he had been doing when distracted by some inconsequential matter. He retired from his job as a technician following his accident and resumed driving his car one month prior to the evaluation.

Upon testing with the IADL Profile, he had a total score of 63 out of a possible 116 points. More specifically, he was dependent for the tasks of going to the grocery store and shopping for groceries (score: 0/4.0), independent to have a meal with guests and clean up after the meal (score: 4.0/4.0), independent to put on outdoor clothing (score: 4.0/4.0), required verbal assistance for all operations related to the task of obtaining information (score: 2.0/4.0), and was dependent to make a budget (score: 0/4.0). To prepare a hot meal for unexpected guests (score: 3.25/4.0), he independently formulated the goal, was independent with difficulty to plan the task, required verbal assistance to carry it out and independently verified attainment of the goal. Overall, he was thus found to have no difficulty with simple routine tasks but had progressively greater difficulty as task complexity increased. A notable difficulty was documented with the capacity to adapt to novel situations as TN tended to be inflexible in his habits and routines, e.g. he had eaten soup for lunch every day for the last 8 weeks.

\section{Participant THF}

THF was a 19-year-old man who sustained a moderate TBI subsequent to a car accident 3.5 months prior to our evaluation. His Glasgow Coma Scale score at emergency was 13/15. He had amnesia of the events surrounding his accident. A CT scan completed at admission to the trauma centre revealed a right subarachnoid haemorrhage and bilateral intraventricular haemorrhage. An audiology report revealed a bilateral mixed auditory loss, more pronounced in the right ear. At the time of testing, he had returned home to live with his parents with whom he had lived prior to this accident. He had not returned to his prior employment as a sanitary agent nor had he resumed driving. At the time of testing, he was attending a rehabilitation program 4 times per week and spending the rest of his days mainly watching television. He complained of some physical deficits such as decreased strength and fine motor ability on his left side as well as loss of taste. Cognitively, he reported having less memory and less concentration than prior to his accident.

Upon testing with the IADL Profile, he had a total score of 75 out of a possible 116 points. More specifically, he required verbal assistance from the examiner to formulate the goal and plan the tasks of going to the grocery store and shopping for groceries (score: 2.75/4.0), independent with difficulty to have a meal with guests and clean up after the meal as he ate on the same plate on which he had earlier put his raw poultry without first washing it and was highly inefficient when cleaning up after the meal (score: 3.57/4.0), independent to put on outdoor clothing (score: 4.0/4.0), was dependent to plan, carry out and verify attainment of the goal for the task of obtaining information (score: 0/4.0), and was dependent to make a budget (score: 0/4.0). To prepare a hot meal for unexpected guests (score: 3.0/4.0), he independently formulated the goal, required verbal assistance to decide upon a menu, required verbal assistance to initiate the task and independently verified attainment of the goal. Overall, he was found to have limited difficulty with simple routine tasks but had progressively greater difficulty as task complexity increased. Moreover, planning ability was limited in a non-structured and unfamiliar context. In fact, when THF was confronted with a situation without an obvious solution, he thought of several alternatives but had great difficulty making a choice. In this type of situation, THF tended to stop the task 
each time he was confronted with a new barrier or when he failed to find a solution.

\subsection{IADL Profile Evaluation}

The Instrumental Activities of Daily Living (IADL) Profile was developed to assess independence with a focus on executive functioning within a series of goal directed IADLs performed in the person's home and several validation studies have been completed [1] [3] [15] [16]. During the IADL Profile administration and scoring, the examiner observes the person's ability in formulating, planning and carrying out functional goals, ability to detect and auto-correct errors as well as his/her ability to self-evaluate performance. One of the IADL Profile activities, "Obtaining Information", involves finding a schedule of bus departures for a trip to a neighbouring city and was the focus of the present study. The evaluator asks the person to verbalize his/her understanding of the task instructions and to say how he/she intends to go about reaching the goal before beginning the task. This strategy allows one to access the plan the individual has in mind. Then, the individual is expected to carry out the task. No material is provided and no means of finding the information is suggested. The examiner essentially sits back and lets the person proceed without interrupting so as to maximize the opportunity to document the person's level of independence in all task components: planning, carrying out the task and verifying goal attainment. To this end, the person is informed at the outset of the evaluation that she is to do the task as though she was alone and had this task to complete. If difficulties arose, the examiner did not immediately respond, allowing the person the time to work through the problem, in which case the score would be 3 , independence with difficulty. However, in the event that the person was unable to do any task operation on his/her own, in spite of the extra time, the examiner provided verbal or physical assistance. Verbal assistance was provided to assist with cognitive deficits and physical assistance for physical deficits to limit the person's distress or discomfort. Scoring was as follows: score 2, when the person required verbal or physical assistance; score 1, in case the person required both verbal and physical assistance. Examiner interventions were kept to a minimum, in order to not "think for" the person and as well to document optimal ability. In the event that the examiner judged that she basically had thought through the task for the person, the score decreased to 0 to indicate dependence.

\subsection{Material and Analyses}

Video recordings of OT examiner and TBI participant interactions occurring within the context of the "Obtaining Information" task of the IADL Profile were viewed repeatedly. Both individuals lived in surrounding towns beyond the suburbs of Montreal, approximately $80 \mathrm{~km}$ away, and the recordings were made in their homes

Verbatim transcriptions were performed by two authors (J.V., A.Z.) until agreement was reached. Conversational analyses of verbatim transcriptions were performed with the intention to understand what was verbal assistance, how it was provided and how it contributed to shape the interactions [13] [17] [18]. These were read and reread. Every turn at talk (T) was identified and coded by two authors (J.V., A.Z.) with QDA-Miner-v3 software [19] to reflect all microstructure events. Each turn was coded inductively, i.e., without a preconceived coding scheme. Rather two authors (J.V., A.Z.) separately identified potential situations where verbal assistance was provided, along with the signals that preceded assistance. The participants' behaviour following the assistance was also described to document the immediate impact of the assistance. Minor terms including discourse markers, i.e., ok, well, right, were coded as such but were not considered assistance.

The initial coding scheme detailed over one hundred different behaviors pertaining to both the evaluator and the participants. In order to allow comparisons, similar codes were grouped into larger categories. The process of synthesizing and validating the categories required numerous consensus discussions, parallel coding on the part of the authors (G.L.D., A.Z.) with reorganisation of the coding scheme as needed. Transparency of the coding process was ensured with definitions of each type of assistance, and corresponding extracts a well as by a review of all the codes and validation the final interpretation performed by G.L.D. and M.M.T.

\section{Results}

Within the obtaining information task of the IADL Profile, the examiner formulates a request which she expects the participants to fulfill. Her intention is to ensure that participants succeed in fulfilling the request to the best of their ability with as little assistance as possible. However, several types of verbal assistance (e.g. restarting, scaffolding, cueing, action priming) were necessary for both participants to succeed. These were defined and illustrated with examples from each participant (see Table 1). For each participant, we included two excerpts of 
Table 1. Types of verbal assistance and definitions.

\begin{tabular}{ll}
\hline Type of verbal assistance & $\begin{array}{l}\text { Definition } \\
\text { Restarting }\end{array}$ \\
$\begin{array}{l}\text { Used to revive a participant's thinking and/or planning operation when he provided a signal that his search was } \\
\text { over. Restarting assistance was also provided to restate some aspect of the context of the evaluation or the in- } \\
\text { structions in order to facilitate the re-engagement of a participant in planning. }\end{array}$ \\
Scaffolding & $\begin{array}{l}\text { Employed to bring to a participant's attention an element of a previous response that was either valid, in need of } \\
\text { correction or that required specification. }\end{array}$ \\
Cueing & $\begin{array}{l}\text { Utilized to provide a participant with an extra bit of information in order to help him progress. } \\
\text { Action priming }\end{array}$ \\
Suggestion of a strategy & $\begin{array}{l}\text { Given to help a participant with an anticipated problem to continue with the elaborated plan. } \\
\text { Supplied to a participant when there appeared to be no other indirect way to help him progress, as he had stopped } \\
\text { searching and all other possible types of assistance had previously been provided without success. }\end{array}$ \\
\hline
\end{tabular}

conversation. All of the codes of the interaction appear in a separate Appendix, Appendix 1 for participant TN and Appendix 2 for participant TNF. A qualitative description of the interaction follows.

\subsection{Participant TN}

The interaction between TN and the examiner lasted approximately 25 minutes and involved 185 turns. The participant was involved in planning from turns T8 through T123. Subsequent turns concerned the execution and feedback phases. The codes for the interaction are provided in Appendix 1, beginning after the instructions. 19 statements of assistance were found. Of these, three of them included more than one type of assistance within the turn.

After the instructions, the participant stated a possible means of finding the departure times by going on the Internet. Action priming led to him mentioning his lack of experience and he objected to doing the task. The next restarting assistance led the participant to digress. He remembered and described past events of his life where he had taken the train but not the bus, jobs he had held, and the conditions of his work, all without interruption by the examiner who only provided listening turns. When he ended his reminiscence, the examiner restarted his search with an indirectly worded request: "So what do you think about what I am suggesting you do, is that something that... you think you could try to do?” at T48. This resulted in him thinking about the information service (411), although incorrectly naming it 911, which is the emergency number in Canada. He failed to explore this idea, however. More restarting assistance got him to think about someone who might know about busses. He thought about "the guy at the cigarette shop" where busses stopped and where tickets were sold in the past. Scaffolding assistance about the cigarette shop led to digressions and a memory of his brother's visit by bus. He was not able to capitalise on this idea at that moment as he seemed caught up in the cigarette shop theme. He elaborated more saying that this guy would not willingly provide bus information and then spoke about taking the bus in the past. Restarting assistance was necessary again to get him to think of ways to find the solution: "Ok (taking her glass of water), so, if you wanted to do what I'm asking you to do, what would you do"? (T72) He then provided vague descriptions of who he could phone to ask about busses and then mentioned his wife would know how to find the bus schedules. The examiner found a humorous way to tell him that he was expected to find the solution. He ended this sequence with a statement of ignorance (T85) as can be seen in excerpt 1, Table 2. The examiner provided restarting assistance with a confronting question: “you have no idea?”(T86) to which TN responded with what he knew how to do, i.e., get to destination by car (T87). In T88, the examiner recognized that he was better at finding a personal solution, and that it was more difficult for him to find the expected solution by bus, an indirect restarting cue (T88). This assistance gave TN the opportunity to discuss his lack of experience with busses in T89 and T91, which he had previously mentioned in T10 and T23. In reaction to the implied admission of incompetence on his part, the examiner cued the search he should be performing (i.e. finding the name of the bus company) by asking whether he knew about a bus company (T92), which was likely since this is common knowledge as there is only one bus company that provides long distance service. Although in T93 TN mentioned the bus that came by his house, and not the name of the company that was expected, his further elaboration in T95, where he admitted not knowing the bus' specifics, suggested that he did not think his response was very good. In T96, the examiner used restarting assistance again to stimulate TN in continuing to think about what he knew. This led to several turns where TN discussed busses and as can be seen in T97 and 
Table 2. Excerpt 1 for TN (T85-T99).

\begin{tabular}{|c|c|c|}
\hline Turn & Speaker & Verbatim \\
\hline T85 & $\mathrm{TN}$ & I have no idea. \\
\hline T86 & $\mathrm{E}$ & You have no idea? ${ }^{\mathrm{a}}$ \\
\hline T87 & $\mathrm{TN}$ & $\begin{array}{l}\text { No, but I know that if I wanted to go to Ottawa, if I wanted to go by car, you take a right and you } \\
\text { take the } 401 \text { to Toronto, it's before Nicolas road, you leave... }{ }^{1} \text { and you get there. Toronto is past Kingston. }\end{array}$ \\
\hline T88 & $\mathrm{E}$ & It’s a little easier by car hey; it’s a little more complicated by bus? ${ }^{a}$ \\
\hline T89 & $\mathrm{TN}$ & Me I’ve always taken, I’ve never taken the bus. \\
\hline T90 & $\mathrm{E}$ & Ok. \\
\hline T91 & $\mathrm{TN}$ & I'd look bad on a bus, me. \\
\hline T92 & $\mathrm{E}$ & Do you know a company, that ... a bus company or...? ${ }^{\mathrm{b}}$ \\
\hline T93 & $\mathrm{TN}$ & (Shrugs his shoulders and shakes his head) ${ }^{2}$. Well, the bus that comes by here (points to the street). \\
\hline T94 & $\mathrm{E}$ & Yeah. \\
\hline T95 & TN & I don’t even know what it is. \\
\hline T96 & $\mathrm{E}$ & You don’t know? ${ }^{a}$ \\
\hline T97 & $\mathrm{TN}$ & I know there's a bus or two-no more—-that go by here a day. \\
\hline T98 & $\mathrm{E}$ & Ok \\
\hline T99 & $\mathrm{TN}$ & $\begin{array}{l}\text { But maybe they go on the other side of the river. Maybe busses go more by Ontario because the roads are } \\
\text { better than here. }\end{array}$ \\
\hline
\end{tabular}

Notes: ${ }^{\mathrm{a}}$ Restarting; ${ }^{\mathrm{b}}$ Cueing; ${ }^{1}$ Short silences of approximately one second are indicated with three dots; ${ }^{2}$ Nonverbal behaviors are indicated in parentheses.

T98, other digressions.

Excerpt 2 (Table 3) begins with TN's last statement about roads in T106. In T107, beginning with "so", indicating a change of topic, the examiner provided restarting assistance and action priming by asking him if he could try out one of his previously stated ideas, implicitly referring to telephoning the information center which he had incorrectly named as "911" in T51, with the suggestion to try and see if he could find something, which could be considered as scaffolding assistance. This last turn was effective in orienting the participant to the task and he objected to the task because of one of the difficulties it involved (T108), again showing how he was remembering the task. In T109, the examiner validated his suggested line of action and used the same vocabulary employing a humorous tone with laughter. In T110, TN began by saying that he did not know anyone that he could call in his town but he also appeared to remember for the second time the event involving his brother who had needed bus schedule information. In T112, he corrected his prior statement, in that his wife was the one who had made the inquiry about bus schedules, and not his brother. In T114, he attempted a humorous comment about telephones in his town, and this ended in a three second silence during which the examiner waited. In T115, the examiner used scaffolding to get TN to think more about the idea he had just brought up by using the same words TN had previously employed in T112. The assistance provided in T115 seemed to have helped TN progress in that he provided two possible solutions. The first solution of there being a bus stop was not usable but the second idea of looking in the phone book was good. So, in T119, the examiner used both scaffolding and action priming. Action priming was employed, in that she invited TN through the use of a question to act, i.e., "to look and see what you can find", without saying where he should look. However, the implicit reference to what he had previously mentioned about looking in a phone book in T116 represented the scaffolding part of the assistance. TN responded in T120 by asking whether he could just ask his wife for help. In T121, the examiner's negative response to the suggestion was attenuated with humour and laughter, in which he joined. In the following turn, T122, TN appeared to remain uncertain about what to do, yet he mentioned he would look somewhere, the phone book presumably. He was able to get up, find the phone book on a shelf a few steps away and look through it. He subsequently found the name of the bus company where he should call.

In spite of limited experience, TN found how to get the information that the task required, through a lengthy search that he tried to end at numerous moments and with specifically-tuned assistance on the part of the 
Table 3. Excerpt 2 for TN (T106-123).

\begin{tabular}{|c|c|c|}
\hline Turn & Speaker & Verbatim \\
\hline T106 & $\mathrm{TN}$ & $\begin{array}{l}\text { The } 148 \text {, that's it. That's the oldest road. When the } 50 \text { there, when it will be there, it will be easy. So, so the } 50 \text { it goes up } \\
\text { to Gatineau. And then they're supposed to, before two thousand... six, I believe, 2006, I think. It will go there. } \\
\text { ( } 2 \text { s. silence). After that, it will be the rest, so, Buckingham, Lachute, Mirabel and everything. }\end{array}$ \\
\hline T107 & $\mathrm{E}$ & So, for what I’m asking you to do, could you try your idea, see if you can maybe find ah... something? ?a,b $^{\mathrm{a}, \mathrm{c}}$ \\
\hline T108 & $\mathrm{TN}$ & How do I do that other than by bugging people? \\
\hline T109 & $\mathrm{E}$ & Well there are people you can bug and it's their job to be bugged. (Laughter) ${ }^{c}$ \\
\hline $\mathrm{T} 110$ & $\mathrm{TN}$ & Here in Villemont ${ }^{1}$ there aren’t any. I know that my brother when he came from Montreal, he called at Villemont. \\
\hline T111 & $\mathrm{E}$ & Ok. \\
\hline T112 & $\mathrm{TN}$ & Ah not my brother, but my wife called at Villemont for him. \\
\hline T113 & $\mathrm{E}$ & Ok. \\
\hline T114 & $\mathrm{TN}$ & Because we have we, the telephone we (unintelligible) (both laugh). (3 s. silence). \\
\hline T115 & $\mathrm{E}$ & Where did she call at Villemont? (E drinks water). ${ }^{\mathrm{C}}$ \\
\hline T116 & $\mathrm{TN}$ & There must be a bus stop. Or else, looked in the phone book, there's a bus stop. \\
\hline T117 & $\mathrm{E}$ & OK. \\
\hline $\mathrm{T} 118$ & $\mathrm{TN}$ & (Unintelligible). \\
\hline T119 & $\mathrm{E}$ & Do you want to look, see what you can find? $?^{b, c}$ \\
\hline T120 & $\mathrm{TN}$ & Well, can I ask her? (Points in the direction of his wife). \\
\hline T121 & $\mathrm{E}$ & No (both laugh). She's gone, there (laughter). ${ }^{\mathrm{a}}$ \\
\hline T122 & $\mathrm{TN}$ & I don't know, we will look, there. \\
\hline T123 & $\mathrm{TN}$ & $\begin{array}{l}\text { (TN gets up and goes to get the phone book, muttering all the while. Takes the phone book, looks at it, puts it down, } \\
\text { goes to get another one and puts the latter one on the table where they are seated). My glasses. (Goes to look for his } \\
\text { glasses). Ah there they are. (Unintelligible muttering). (Sits down, puts glasses on) Bus. (Silently looks in the phone } \\
\text { book for } 1 \text { min. } 40 \mathrm{~s} \text {.). Ah Voyageur Busses, that must be the one. What did you want to know? You want to know } \\
\text { which bus we take for for ... Villemont ( } 2 \mathrm{~s} \text { s silence) to Toronto? }\end{array}$ \\
\hline
\end{tabular}

Notes: ${ }^{\mathrm{a}}$ Restarting; ${ }^{\mathrm{b}}$ Action Priming; ${ }^{\mathrm{c}}$ Scaffolding; ${ }^{1}$ Villemont is a fictitious name.

examiner. Restarting assistances were mainly successful at getting him re-engaged since he provided reasonable or nearly reasonable answers, also indicating that he remembered what the task was despite digressing. However, he was unable to capitalize on potentially good ideas; rather he segued onto other topics moving away from the task he was to accomplish. Seemingly, TN would not have initiated the action that was expected of him. His overall approach to finding the bus schedules was not proactive, rather he was dependent on the examiner putting him back on track and stimulating him to think of other ideas. Otherwise it can safely be determined that he would have terminated his search before any viable plan would have been developed.

\subsection{Participant THF}

The interaction between THF and the examiner lasted approximately 31 mins, and involved 182 turns. The analysis concerned turns T6 and T149 when the participant searched for a means to accomplish the task. The codes for the complete interaction are provided in Appendix 2. Thirty-one speaking turns provided assistance of some sort. Of these, two of them included several types of assistance within the speaking turn.

After the instructions, the participant stated he would go in person to the bus stop in Montreal (something which is not feasible in the context of the evaluation), and after being asked to provide more ideas, he produced two others which he dismissed however. Following this, the examiner employed restarting numerous times, with little success however, because of THF's apparent inability to understand the implied message that going in person to get the bus schedules was a flawed plan. (See excerpt 1 in Table 4, T21, T27, T29, and T31). The 
Table 4. Excerpt 1 for THF (T20-T31).

\begin{tabular}{|c|c|c|}
\hline Turn & Speaker & Verbatim \\
\hline $\mathrm{T} 20$ & $\mathrm{E}$ & The departure is from Montreal. ${ }^{a}$ \\
\hline $\mathrm{T} 21$ & THF & $\begin{array}{l}\text { It's from Montreal, well that's it. I'd go see ah... either (coughs) I'd go to the bus terminal and I'd get information from } \\
\text { them. Maybe they would know. And after that, I would go from Villedor }{ }^{1} \text { to Montreal by bus. And from Montreal to the } \\
\text { bus terminal in Montreal, well there at Longueuil up to... I'd get information there for ah... which bus I need to take for } \\
\text { ah Toronto. }\end{array}$ \\
\hline $\mathrm{T} 22$ & $\mathrm{E}$ & Hum hum. \\
\hline $\mathrm{T} 23$ & THF & So, that's it. \\
\hline $\mathrm{T} 24$ & $\mathrm{E}$ & $\begin{array}{l}\text { So, if you wanted to give them to me today, because I I'd like to have them today if possible. (THF makes a face). Is there } \\
\text { something that you could do? }^{\mathrm{a}}\end{array}$ \\
\hline $\mathrm{T} 25$ & THF & Ah... No idea. I never took the bus before, so no idea. \\
\hline $\mathrm{T} 26$ & $\mathrm{E}$ & That’s good, you don’t own a car. (Both laugh). ${ }^{\text {b }}$ \\
\hline $\mathrm{T} 27$ & THF & $\begin{array}{l}\text { (Looks at E, looks forward and down). But... I have no idea, the busses (lifts a hand) don't come by here, so ah... I } \\
\text { don't know their schedules. But... Let's say to get them; it would really have to be... (lifts his brows) I'd have to go in } \\
\text { the city to get information about this. For that. Either that or I imagine they have little... pamphlets for ah... all the } \\
\text { destinations, and the times, and all of that. But... (Shakes his head and speaks more softly) apart from that, I have no } \\
\text { idea. I could not get them get them right now... even... That's it. }\end{array}$ \\
\hline T28 & $\mathrm{E}$ & Let's say you need them. Is there something else that you could think of that you could do to try to get them? ${ }^{\mathrm{a}}$ \\
\hline T29 & THF & $\begin{array}{l}\text { Ah...(10 s. silence). No idea. I could maybe go look on the Internet, but I don't know if they have this on Internet... } \\
\text { bus schedules. I don't think so. Apart from that, I have no idea. I could not really get them here at this time. I'd really } \\
\text { need to get information at the terminal. (softly). That's it. Apart from that, ah.... (shakes his head) I see no other solu- } \\
\text { tion. Well, none that comes to mind there (unintelligible). ( } 8 \text { s. silence, shakes his head, eyes looking down, and lifts } \\
\text { his brows). No really no. ( } 20 \mathrm{~s} \text { s. silence, looks out the window, turns towards E and shakes his head). }\end{array}$ \\
\hline Т30 & $\mathrm{E}$ & Shall I give you a few more minutes to think about it? ${ }^{c}$ \\
\hline T31 & THF & $\begin{array}{l}\text { Ha... (embarrassed laughter, crosses his arms while smiling) I really have no idea really, even. I would need to get } \\
\text { information at a bus terminal there. That's really ah... I see... It's the only solution that I see possible there. }\end{array}$ \\
\hline
\end{tabular}

Notes: ${ }^{\mathrm{a} C u e i n g ;}{ }^{\mathrm{b}}$ Restarting; ${ }^{\mathrm{c}}$ Suggestion of a strategy; ${ }^{1}$ Villedor is a fictitious name.

examiner did not spell out directly that the participant's idea of going in person was not acceptable. In T20, T24 and T28, the examiner provided cues to help the participant understand what was requested of him. THF did not appear to understand these cues and persisted with his initial idea of going in person. In turns T24, "Is there something that you could do?" and T28 "Is there something else that you could think of that you could do to try to get them?" the examiner also restarted the participant's thinking for other ideas implying a better plan was needed. In T25 he admitted not having experience in taking the long distance bus. In T27 he became more hesitant about other potential means of finding the solution and he repeated his preferred idea. Although he was able to find another one in T29, looking up the Internet, he dismissed it because he believed this information would not be on the net. He concluded with his preferred solution, and admitted not having other ideas. In T30, the examiner used another type of assistance; in that she explicitly suggested a strategy of more time to think. He again did not realise he needed a more feasible plan. He repeated that he would need to go into Montreal or phone in Montreal and that he had no other ideas, indicating that he had finished the task.

At this point the examiner decided to remind THF that he had made other suggestions and primed him into action by asking whether he could try one of them (T34, T36, T38, T42). This led the participant to think of calling the convenience store where busses presumably stopped to pick up passengers for Montreal. However, he did not feel this was a good idea because he did not know the name of the store. He thought he could look it up in the phone book, but he expressed his ignorance about where he would need to call. A restarting assistance confronting his lack of knowledge, "You don't know if you can look for it?" (T46) led to further explanations about his ignorance but also to an agreement to look in the phone book. THF then proceeded to read the phone book aloud for over three minutes while commenting that the information he was reading was not appropriate even though he was in a section that dealt with busses. At this point he again stated what he could do without any problem, i.e. go in person and what he could not do, i.e. find the information using the phone. The examiner 
tried to get him to choose one of the listed companies (T53) and to think of how he could choose the best one. The discussion continued with THF explaining why the companies were not really good choices. He misunderstood two cues the examiner provided in T61 and T64 that asked him where he could call to get information (referring implicitly to the 411 information service which is public and common knowledge). His response, related to what he was reading in the phone book, "I don't know these places, not at all, it's... I really don't know anything about this" (T65) indicated that he misunderstood the cues. The examiner then took another tack and tried to remind the participant of his previous suggestions and at this point stated explicitly: "other than going in person" (T66). This led to the emergence of the notion of calling someone who takes the bus. He again judged that this plan was not feasible and admitted he was stuck. A further restarting assistance was given to remind him he had mentioned the Internet. However, THF did not think he could find the schedules that way admitting he had difficulty using the Internet now. He concluded this episode with another reiteration of his plan to go to Montreal in person to find the bus schedules.

Following this, another episode involved the examiner negotiating with him to have him call one of the bus terminals listed in the phone book: "Would you be comfortable to call and to ask them where, where you would need to call to get the information? Because we can assume that this is not the right place to call but maybe they could give you the information" (T92). Although THF did the call, he was not able to ask where he should phone to get the bus schedules, therefore leading to another failure he had expected: "Ah... well I don't know if... They'll surely refer me to ... tell me go to Montreal, because according to me, from here to Toronto, they don't do that" (T103). When relating the conversation he said: "She told me: 'Here we don't have anything like that'” (T114). The examiner ended this episode with some explicit advice to get him to think of the 411 information service as can be seen in the beginning of Excerpt 2, at T115. See Table 5. This explicit advice allowed him to name the 411 information service. However, he did not judge this to be a good plan, rather he appeared to continue to search for other ideas in T120 and T122, persevering with previous requests for alternative ideas. Moreover, he was unable to understand that what he had said in T114 was a good solution to the problem and put it into action. The examiner primed him into action and he agreed to make the phone call. However, the examiner suggested a strategy he should practice what he was going to ask for (T127 and T129). His responses in T128 and T130 indicated he could plan and formulate the request. He seemed under the impression that there were multiple bus terminals and was unsure whether he could really obtain the information. THF ended his turn with the statement "I really can't see anything else" (T130), indicating a possible misunderstanding with finding alternatives, or a tendency to perseverate. In T132, THF was unable to act, although his plan was perfect, because he did not understand the implication that since his plan was acceptable, he could now put it into action. Later THF was able to understand that he should put his plan into action, after action priming. Although he formulated an objection to action, in that he believed erroneously that using the 411 service would be a long distance call (in response the examiner offered to pay what he thought it would cost). Eventually he placed the 411 call, obtained the number where he should phone and got the bus schedules.

THF's response to the task was an unfeasible plan, a solution he persisted to think was the best one in spite of extensive implicit feedback to the contrary, indicating poor judgement regarding the adequacy of his plan. He did not have previous experience with taking the long distance bus and he may have been limited as to what he perceived he could do. He was unable to adjust to the constraint of finding the schedules at the moment they were requested of him. He did not have a problem solving approach to the task, rather he appeared stuck with what he knew he could do and did not explore other less well known possibilities and thus he was frequently trying to end the task. Although THF did find other solutions with various forms of assistance, such as consulting the Internet, calling someone who knows, or looking in the phone book, he did not explore these fully without assistance; rather he dismissed them and stopped searching each time, often ending his turns with statements of ignorance concerning other ways of finding the schedules. It is possible he could not inhibit the first plan he had brought up or he was unable to use other ideas to his benefit. Scaffolding assistance was not very effective in moving his thinking forward when he had a potentially good lead and neither were cues. He was unable to locate the number of the bus company while consulting a phone book, a failure to profit from being immersed in this activity as a means of finding a solution. When calling another bus company he was not able to capitalise on this opportunity to find the solution; rather he anticipated failure and this proved to be true. He did not seem to understand implicitly formulated verbal assistance. He required explicit advice to find and call information services, which was the examiner's idea, as well as action priming and further, finding a solution to an obstacle he 
Table 5. Excerpt 2 for THF (T114-T139).

\begin{tabular}{|c|c|c|}
\hline Turn & Speaker & Verbatim \\
\hline $\mathrm{T} 114$ & THF & Really in Montreal... (Hand gesture of helplessness). That's it. \\
\hline T115 & $\mathrm{E}$ & $\begin{array}{l}\text { Ok, so ... Ok. Let's look for another idea. If you want a number, somewhere in Que... in Quebec, is there another } \\
\text { place you can call? }^{\mathrm{a}}\end{array}$ \\
\hline $\mathrm{T} 116$ & THF & If I want [E: let's say $]^{1}$ to get a number somewhere in Quebec? \\
\hline $\mathrm{T} 117$ & $\mathrm{E}$ & Yes. \\
\hline $\mathrm{T} 118$ & THF & Well there's the 411 service. \\
\hline $\mathrm{T} 119$ & $\mathrm{E}$ & Ok. \\
\hline T120 & THF & $\begin{array}{l}\text { Well and apart from that (pointing to the phone book), the phone book. Well here, it's just about this town and other } \\
\text { towns in the area, so ah... the phone book would not be very useful. }\end{array}$ \\
\hline $\mathrm{T} 121$ & $\mathrm{E}$ & Ok. \\
\hline $\mathrm{T} 122$ & THF & $\begin{array}{l}\text { Unless it was somewhere around here. Well that's it, apart from the } 411 \text { service, I can't see what else, what else I } \\
\text { could do... (Looks in the direction of the examiner) (mumbles) }\end{array}$ \\
\hline $\mathrm{T} 123$ & $\mathrm{E}$ & Ok and $411 ?^{\mathrm{b}}$ \\
\hline $\mathrm{T} 124$ & THF & Yeah. \\
\hline $\mathrm{T} 125$ & $\mathrm{E}$ & Is that an alter-... is $\ldots$ is that an alternative that you could look into? ${ }^{c}$ \\
\hline $\mathrm{T} 126$ & THF & Sure, there’s no problem. \\
\hline $\mathrm{T} 127$ & $\mathrm{E}$ & What... what would you do if you called there? ${ }^{\mathrm{d}}$ \\
\hline $\mathrm{T} 128$ & THF & $\begin{array}{l}\text { Well, if we're still talking about bus schedules, I would ask, ah,... the number, well it's because, a bus terminal in } \\
\text { Montreal, they can refer me about anywhere in Montreal, that I don't know if... I wouldn't know... what to ask, that's } \\
\text { because, for the bus schedules, but... a terminal, I wouldn't know which terminal. }\end{array}$ \\
\hline $\mathrm{T} 129$ & $\mathrm{E}$ & Ok. So if you gave a bit more information in your question. What would that be, there, the more information bit? \\
\hline $\mathrm{T} 130$ & THF & $\begin{array}{l}\text { THF: Well, they, they, they... I don't know if they can do something for that, but... I'd tell them that it's for finding } \\
\text { out the bus schedules... for ah ... for going to Toronto, so to find out, that you refer me to... to someone who can, who } \\
\text { can answer me on that subject. I really can't see anything else. }\end{array}$ \\
\hline $\mathrm{T} 131$ & $\mathrm{E}$ & OK. \\
\hline $\mathrm{T} 132$ & THF & (15 s. silence. THF turns towards E and gestures helplessness) (E laughs) \\
\hline $\mathrm{T} 133$ & THF & What is going on? (Both laugh). \\
\hline $\mathrm{T} 134$ & $\mathrm{E}$ & You are thinking too much about what’s in your head. \\
\hline $\mathrm{T} 135$ & THF & Yes (Looking intently at the phone book. Both laugh). Ah yeah, but I don’t know what to do. \\
\hline $\mathrm{T} 136$ & $\mathrm{E}$ & Ok. \\
\hline $\mathrm{T} 137$ & THF & I'll answer the question and ah. \\
\hline $\mathrm{T} 138$ & $\mathrm{E}$ & Ok and that. Is that, is that... Can you do this? \\
\hline $\mathrm{T} 139$ & THF & The 411 service? \\
\hline
\end{tabular}

Notes: ${ }^{\mathrm{a} E x p l i c i t ~ h e l p ; ~}{ }^{\mathrm{b}}$ Scaffolding; ${ }^{\mathrm{A}}$ Action priming; ${ }^{\mathrm{d}}$ Suggestion of a strategy; ${ }^{1}$ Overlapping segment indicated in square parentheses.

thought prevented him from making the phone call. The participant was dependent on the examiner who provided more and more explicit assistance.

\section{Discussion}

The aim of this exploratory study was to examine how functional performance in IADL evaluations can be supported by verbal assistance provided by experienced occupational therapists within an interaction with individu- 
als with TBI. Our detailed analyses identified several types of verbal assistance, provided in response to signals in the participants' talk that indicated difficulty in formulating an adequate plan that could later be put into action. Verbal assistance was frequently provided to restart a participant's thinking when difficulties arose: digressions, typical of TN, or an inadequate plan, which typified THF. Within the context of this IADL evaluation the examiner's intention is to get the participants to succeed. However, because failure can be observed very quickly after the instructions are provided, the examiner needs to constantly restart the participants' search for a plan to fulfill the request. In other words the examiner needs to reformulate the request numerous times, without being direct or repetitive because this could antagonise the person being evaluated. Therefore requests to restart searching for a plan took on different forms which are related to what participants brought up as reasons for wanting to discontinue: objection, refusal to continue, belief that the best has already been done, admission of failure or a, lack of appropriate means to find something. In that respect, this evaluation procedure differs from others where errors or failures usually signal the end of the task.

All verbal assistance types did not have the same effect on the participants' performance. Overall, THF required far more instances of assistance than TN. He required more direct forms of verbal assistance and strategies to enable him to eventually accomplish the task. The restarting assistance was not facilitative for THF who did not appear to understand implicit messages. It did however help TN renew his search for more optimal alternatives to solve the problem. Action priming helped TN access his knowledge while looking in the phonebook, but this type of assistance did not help THF, possibly because he did not understand the implication that his plan was appropriate. He also did not respond well to cues, probably because they required that an inference be made.

The process of providing verbal assistance can best be understood as a general strategy of supported thinking. For supported thinking to occur, the therapist encourages the person to talk out loud. Some of the principles of supported thinking that appeared to be guiding the experienced evaluator were to give the person time to think, ask open-ended questions, ask several times in different ways, be respectful, not point out errors, not encourage or discourage digressions and validate the correct elements. The evaluator acted as a resource to get participants to formulate a workable plan that could then be put into action.

To facilitate the person's thinking the therapist was attentive to the signals emitted by the participants. When an element of value was produced it was used in scaffolding assistance. Moreover, verbal assistance varied as the interaction unfolded and the individuals progressed or not, in that certain forms of assistance occurred earlier on in the interaction while others occurred later. Restarting was the main form of assistance provided in the early part of the interaction, as well as later on when participants stopped their search, followed by scaffolding or cueing and action priming if a feasible plan had emerged. Cues and more direct forms of assistance occurred later on in the interaction after other attempts had apparently failed.

This process of providing progressive and focussed verbal assistance can contribute to our understanding of the client's underlying cognitive difficulties, or more specifically, the repercussions of these difficulties on task performance. Here the underlying difficulties of the participants differed and were observed in a natural and relatively unconstrained context, allowing one to understand the repercussions of TBI in daily life. None of the participants had a lot of experience with long distance busses and may have had difficulty in retrieving a low frequency plan. They both lived a significant distance away from a large city, which complicated the task to some extent because the busses' departure point was not from their home town. This required them to imagine a solution which did they had never or rarely practiced, requiring a problem solving approach and inferential thinking, which they were unable to muster on their own.

TN's planning was limited by slow and divergent thinking, and a tendency to stop thinking and searching. However, when engaged in verbalising his thoughts, he was able to explore his memory. The verbal digressions proved useful in that he was able to find pertinent bits of information that were highlighted by the examiner and he apparently used this information to find a solution.

An incorrect understanding of the task instructions may have hindered THF and this led him to formulate an inadequate plan. Attempts to indirectly correct his comprehension failed. Independently of his comprehension or comprehension problems, he was unable to judge that his plan was inadequate. His thinking was later hindered by a tendency to respond with alternatives even when the examiner was requesting only one idea. He required repeated invitations to act before he understood that his plan was a good one. He may have had the tendency to fail to initiate action. However, once he knew what was expected of him, he did not seem to mind putting himself into action. Yet, when in action, he was not able to access usable information to solve the problem. He 
appeared unable to deduce or access knowledge about the event he was trying to plan. He needed explicit and direct questions that allowed him to think of a solution and finally solve the problem. It is likely that THF had difficulties with inferential comprehension, and not understanding when he had things right or wrong.

The difficulties of both of these participants, digressions and difficulty understanding inferences are quite typical of the cognitive-communication difficulties observed in a TBI population [6]. From a therapeutic point of view, it is possible that the participants benefitted from verbalizing their thinking and searching for ideas out loud within a facilitative interaction. Such experiences could provide a basis for interventions that allow patients with TBI to succeed in spite of significant problems. With repeated opportunities to plan how to solve problems, without being told what to do but by thinking out loud and receiving adjusted assistance, patients with TBI may learn to access their residual cognitive potential and eventually improve their level of functioning. The present results indicate that fine-tuned verbal assistance plays a significant role in facilitating performance. Hence a more complete understanding of verbal assistance appears to be a worthy area of future investigation.

The primary limitation of this study is the fact that two participants were studied within only one of the tasks of the IADL Profile. Further studies should include a larger number of participants with varied cognitive difficulties to ensure that all potential types of verbal assistance that can be used by an examiner within this context have been captured. An enhanced understanding of when and how verbal assistance is best delivered to optimize function could serve in the training of therapists who are expected to not only evaluate the extent of cognitive deficits but also to describe what strategies or facilitators seem to help a patient in functioning or being independent. Further studies could examine the performance of participants in some of the other types of tasks, such as planning a meal or shopping for food, which could reveal the extent to which cognitive limitations interfere with other types of daily activities and which types of assistance facilitate performance in other tasks. These further studies could provide us with indications as to the conditions that ensure the independence of people who have cognitive limitations related to traumatic brain injury.

\section{Conclusions}

This study reveals that verbal assistance is more than a graded series of prompts that are dispensed in an arbitrary fashion. The process of providing non-intrusive verbal assistance within the context of the IADL Profile evaluation provides a form of supported thinking for participants with cognitive deficits; "supported" because the therapist does not think for the person but rather attempts to facilitate the person's own residual ability to think the problem through. It seeks to identify the person's optimal task-related abilities. In this study, the tendency to stop searching for a solution appeared to be the most dominant kind of cognitive limitation experienced by both participants with TBI. Our results demonstrate that a speaker can provide support for executive functioning to a person with TBI by delivering specific assistance. Moreover, such a speaker needs to remain engaged with the person and to attend to his/her attempts at solving a problem without thinking the task out; invite the person with TBI to verbalize his/her thoughts and allow extra time for thinking and exploring; emphasize the ideas the person with TBI brings up; avoid confronting or bringing up errors; believe that the person with TBI will eventually formulate and clarify his/her ideas. In all likelihood, delivering verbal assistance in such a manner requires experience or training.

Further explorations of interactions between an experienced occupational therapist and persons with a TBI involved in IADL activities should allow us to not only better understand the concept of verbal assistance but also how it is weaved into an interaction that eventually allows persons with a TBI to complete a challenging planning task.

\section{Acknowledgements}

This study was supported by an ONF-REPAR (Ontario Neurotrauma Foundation-Reseau de Recherche Provincial en Adaptation-Réadaptation) research grant and research funds available to the first and to the senior authors at the Centre for Interdisciplinary Research in Rehabilitation of Greater Montreal. We thank the participants. We also thank our students who provided assistance for this work: Judith Roberge and Paola Araya Valdes.

\section{References}

[1] Bottari, C., Dassa, C., Rainville, C. and Dutil, E. (2009) The Criterion-Related Validity of the IADL Profile with 
Measures of Executive Functions, Indices of Trauma Severity and Sociodemographic Characteristics. Brain Injury, 23, 322-335. http://dx.doi.org/10.1080/02699050902788436

[2] Godefroy, O., Azouvi, P., Robert, P., Roussel, M., LeGall, D. and Meulemans, T., Groupe de Reflexion sur l'Evaluation des Fonctions Executives Study (2010) Dysexecutive Syndrome: Diagnostic Criteria and Validation Study. Annals of Neurology, 68, 855-864.

[3] Bottari, C., Dassa, C., Rainville, C. and Dutil, E. (2009) The Factorial Validity and Internal Consistency of the Instrumental Activities of Daily Living Profile in Individuals with a Traumatic Brain Injury. Neuropsychological Rehabilitation, 19, 177-207. http://dx.doi.org/10.1080/09602010802188435

[4] Gillen, G. (2009) Cognitive and Perceptual Rehabilitation. Mosby/Elsevier, St. Louis.

[5] Baum, C.M., Connor, L.T., Morrison, T., Hahn, M., Dromerick, A.W. and Edwards, D.F. (2008) Reliability, Validity, and Clinical Utility of the Executive Function Performance Test: A Measure of Executive Function in a Sample of People with Stroke. The American Journal of Occupational Therapy, 62, 446-455. http://dx.doi.org/10.5014/ajot.62.4.446

[6] Ylvisaker, M., Szekeres, S.F. and Feeney, T. (2008) Communication Disorders Associated with Traumatic Brain Injury. In: Chapey R., Ed., Language Intervention Strategies in Aphasia and Related Neurogenic Communication Disorders, 5th Edition, Lippincott Williams \& Wilkins, Philadelphia, 879.

[7] Togher, L., Hand, L. and Code, C. (1997) Analysing Discourse in the Traumatic Brain Injury Population: Telephone Interactions with Different Communication Partners. Brain Injury, 11, 169-190. http://dx.doi.org/10.1080/026990597123629

[8] Togher, L., Taylor, C., Aird, V. and Grant, S. (2006) The Impact of Varied Speaker Role and Communication Partner on the Communicative Interactions of a Person with Traumatic Brain Injury: A Single Case Study Using Systemic Functional Linguistics. Brain Impairment, 7, 190-201. http://dx.doi.org/10.1375/brim.7.3.190

[9] Togher, L. and Hand, L. (1999) The Macrostructure of the Interview: Are Traumatic Brain Injury Interactions Structured Differently to Control Interactions? Aphasiology, 13, 709-723. http://dx.doi.org/10.1080/026870399401821

[10] Togher, L., McDonald, S., Code, C. and Grant, S. (2004) Training Communication Partners of People with Traumatic Brain Injury: A Randomised Controlled Trial. Aphasiology, 18, 313-335. http://dx.doi.org/10.1080/02687030344000535

[11] Simmons-Mackie, N. and Damico, J. (1999) Social Role Negotiation in Aphasia Therapy: Competence, Incompetence and Conflict. In: Kovarsky, D., Duchan, J. and Maxwell, M., Eds., Constructing (In)Competence: Disabling Evaluations in Clinical and Social Interaction, Lawrence Erlbaum, Hillsdale, 313-342.

[12] Simmons-Mackie, N. and Damico, J. (2008) Exposed and Embedded Corrections in Aphasia Therapy: Issues of Voice and Identity. International Journal of Language \& Communication Disorders, 43, 5-17. http://dx.doi.org/10.1080/13682820701697889

[13] Horton, S. (2006) A Framework for Description and Analysis of Therapy for Language Impairment in Aphasia. Aphasiology, 20, 528-564. http://dx.doi.org/10.1080/02687030600590130

[14] Bottari, C.L., Dassa, C., Rainville, C.M. and Dutil, E. (2010) The IADL Profile: Development, Content Validity, Intraand Interrater Agreement. Canadian Journal of Occupational Therapy, 77, 90-100. http://dx.doi.org/10.2182/cjot.2010.77.2.5

[15] Bottari, C., Dassa, C., Rainville, C. and Dutil, E. (2010) A Generalizability Study of the Instrumental Activities of Daily Living Profile. Archives of Physical Medicine and Rehabilitation, 91, 734-742. http://dx.doi.org/10.1016/j.apmr.2009.12.023

[16] Bottari, C., Gosselin, N., Guillemette, M., Lamoureux, J. and Ptito, A. (2011) Independence in Managing One’s Finances after Traumatic Brain Injury. Brain Injury, 25, 1306-1317. http://dx.doi.org/10.3109/02699052.2011.624570

[17] Potter, J. (2004) Discourse Analysis. In: Hardy, M. and Bryman, A., Eds., Handbook of Data Analysis, SAGE Research Methods, 607-642. http://dx.doi.org/10.4135/9781848608184.n27

[18] Sacks, H., Schegloff, E. and Jefferson, G. (1974) A Simplest Systematics for the Organization of Turn-Taking in Conversation. Language, 50, 696-735. http://dx.doi.org/10.2307/412243

[19] QDA Miner (Computer Program). Version 3.2, Provalis Research, Montreal, 2007. 


\section{Appendix 1}

Types of verbal assistance, TN's responses and the outcome of the assistance per speaking turn (indicated in parentheses)

Type of verbal assistance

Restatement of task instructions (T17) ${ }^{* *}$

Action priming (T19)

Restarting and action priming (T21)

Restarting (T24)

Acknowledgements (T26-T46) ${ }^{* *}$

Restarting (T48)

Scaffolding (T50)

Acknowledgement (T52)

Restarting (T54)

Acknowledgement (T56)

Scaffolding (T58)

Scaffolding (T62)

Restarting (T72)

Scaffolding (T74)

Acknowledgement (T76)

Looks at TN (T78)

Acknowledgement (T80)

Restarting (T82-T84)

Restarting (T86)

Restarting (T88)

Acknowledgement (T90)

Cueing (T92)

Acknowledgement (T94)

Restarting (T96)

Restarting, action priming and scaffolding (T107)

Scaffolding (T109)

Acknowledgement (T111)

Acknowledgement (T113)

Scaffolding (T115)

Acknowledgment (T117)

Scaffolding and action priming (T119)

Restarting (T121)

TN's responses

Outcome

States idea $1^{* * *}(\mathrm{~T} 18)$

States ignorance (T20)

$\mathrm{U}$

Long silence, states ignorance (T22) Objects (T23) U

Digresses about first time on trains (T25)

Digresses about previous jobs (T27-T47)

Formulates idea 2 with an error (T49)

$\mathrm{S}$

Does not correct error or elaborate (T51)

States ignorance (T53)

States ignorance (T55)

Formulates idea 3 (T57)

Digresses about cigarette shop (T59-T61)

$\mathrm{U}$

Reminiscence about brother’s visit, digresses cigarette shop (T63-71) U

Formulates idea 4 (T73)

S

Formulates alternative 4a (T75)

Long silence, states ignorance (T77)

Formulates alternative 4b (T79)

Suggests wife, idea 4c (T81)

States ignorance (T85)

\section{Excerpt 1 begins}

Digresses driving solution (T87) U

States lack of experience (T89)

States lack of experience (T91) U

Formulates idea 5 (T93)

States ignorance (T95) $\quad$ S/U

Digresses on busses, roads (T97-T106) U

\section{Excerpt 1 ends and excerpt 2 begins}

Objects (T108)

Reminiscence about brother's visit (T110) S

Continues reminiscence (T112)

Attempts to joke, silence (T114)

Formulates ideas 6 and 7 (T116) S

Unintelligible response (T118) -

Suggests idea 4c (T120) S

Agrees to do task, gets phone book, finds name of bus company (T122-123)

\section{End of excerpt 2}

Notes: *S: Successful; U: Unsuccessful. S/U was used when the participant first benefited from the verbal assistance, but was not ultimately successful either because he digressed or dismissed an idea on the same speaking turn or a subsequent turn. ${ }^{* *}$ These turns were not considered to provide verbal assistance. Acknowledgements included listening turns and discourse markers, such as yeah, ok, good. ${ }^{* * *}$ Ideas: 1 -Internet [first response after instructions]; 2-Take the phone and call 911; 3-Ask the guy at the cigarette shop; 4-Ask somebody he knows: a-friends; b-names person; c-wife; 5-Bus that passes close to his house; 6-Call the bus stop; 7-Look it up in the phone book. 


\section{Appendix 2}

Types of verbal assistance, description of THF's responses and the outcome of the assistance per speaking turn

Type of verbal assistance

Provides task instructions (T5)

Restarting (T7)

Restarting (T9)

Unintelligible (T11)

Restarting (T13)

Restarting (T15)

Restarting (T17)

Cueing (T18)

Reformulation of previous cue (T20)

Acknowledgement (T22)

Restarting (T24)

Restarting (T26)

Cueing (T28)

Suggestion of a strategy (T30)

Acknowledgement (T32)

Scaffolding and action priming (T34-36-38-42)

Acknowledgement (T44)

Restarting (T46)

Acknowledgement (T48)

Restarting (T53-55)

Aborted cueing (T57)

Acknowledgement (T59)

Cueing (T61)

Cueing (reformulated previous cue) (T64)

Scaffolding and cueing (T66)

Scaffolding (T68)

Explicit advice (idea 4) (T70)

Scaffolding (T72)
THF's responses

Outcome*

Formulates idea $1^{* * *}$ (T6)

Formulates ideas 2 and 3, dismisses idea 2, ends search (T8) S/U***

Laughter, objects jokingly (T10) U

Laughter (T12) U

Acknowledges (T14) U

Repeats idea 1 (T16) U

No answer

Acknowledges (T19) U

\section{Excerpt 1 begins}

Elaborates idea 1 (T21)

Ends search (T23)

States ignorance about busses (T25) U

States ignorance, elaborates idea 1, pauses (T27) U

Pauses, states ignorance, formulates idea 4, dismisses idea 4, repeats idea 1, states ignorance, ends search (T29)

$\mathrm{S} / \mathrm{U}$

States ignorance, repeats idea 1, ends search (T31)

\section{End of excerpt 1}

States ignorance, pauses, hesitates, restates idea 2, states ignorance (T33)

Acknowledges (T35, 37), validates understanding (T39), pause, states idea 5 and ignorance (T43)

Formulates idea 6, states ignorance (T45) S/U

States ignorance, unsure about idea 5, agrees to do idea 6 (T47) S

Gets phone book (T49)

Reads aloud (T50-T51)

Reads aloud, pauses, rejects the possibilities, states ignorance about -

phoning but knows how to do it on his own [3 minutes] (T52)

Hesitates (T54) Reads aloud and states ignorance (T56) U

Describes the information (T58) S

Explains (T60)

Misunderstands, elaborates on what he is reading (T62) U

Long pause, states ignorance(T63)

States ignorance (T65) U

Restates idea 3, dismisses idea 3, states stuck (T67) S/U

Admits lost (T69) U

Acknowledges (T71) $\quad$ S/U

Elaborates idea 4, dismisses idea 4, states ignorance (T73) S/U 


\section{Continued}

Acknowledgement (T74)

Acknowledgement (T76)

Scaffolding (T78)

Scaffolding pursued (T80)

Restarting (T82)

Restarting (T84)

Explicit advice (T87-88)

Scaffolding (T90)

Action priming, explicit advice and scaffolding (T92)

Acknowledgement (T94)

Acknowledgement (T96)

Suggestion of a strategy (T98)

Scaffolding (T100)

Acknowledgement (T102)

Restarting (T104)

Action priming (T106)

Acknowledgement (T108)

Restarting (T111)

Explicit advice (T115)

Acknowledgement (T117)

Acknowledgement (T119)

Acknowledgement (T121)

Scaffolding (T123)

Action priming (T125)

Suggestion of a strategy (T127)

Scaffolding (T129)

Acknowledgement (T131)

Action priming (T134)

Acknowledgement (T136)

Action priming (T138)

Acknowledgement (T140)

Suggestion of a strategy (T142)
Objects to idea 4 (T75)

States ignorance (T77)

Dismisses idea 4 (T79)

$\mathrm{U}$

States ignorance (T81)

$\mathrm{U}$

Elaborates on idea 1, stops search (T83) U

Gestures ignorance (T85)

States ignorance (T86)

Elaborates on phone book (T89) U

Acknowledges (T91)

\section{$\mathrm{U}$}

Completes sentence (T93)

\section{S}

Validates understanding (T95)

Accepts to do task, hesitates (T97)

Practices and elaborates (T99) S S

Validates understanding (T101) S

Objects (T103)

Elaborates on assistance, stops search (T105) U

Acknowledges (T107)

Gets the phone (T109)

Executes first call (T110)

Repeats some of the phone conversation, gestures helplessness, stops search (T112-T114)

\section{Excerpt 2 begins}

Validates understanding (T116)

Formulates idea 7 (T118)

Elaborates on idea 6, dismisses it. (T120) S/U

Elaborates on idea 6, dismisses idea 7, states ignorance (T122) S/U

Acknowledges (124) U

Agrees to accomplish task (T126) S

Practices and elaborates, states ignorance (T128) S/U

Practices, elaborates, stops search (T130)

Long pause, gestures helplessness (T132) S/U

Validates understanding (133)

States ignorance (T135)

Agrees to do the task (T137)

Validates understanding (T139)

\section{End of excerpt 2}

Agrees to do the task, objects (T141)

$\mathrm{S} / \mathrm{U}$

Agrees, digresses (T143) 


\section{Continued}

Elaboration on suggested strategy (T144)

Further elaboration on suggested strategy (T146)

Acknowledgement (T148)
Acknowledges (T145)

Turns phone on and off. Asks to think about what he will say (T147)

Long pause, phones (T149)

\section{S}

S

Notes: *S: Successful; U: Unsuccessful. S/U was used when the participant first benefited from the verbal assistance, but was not ultimately successful either because he digressed or dismissed an idea on the same speaking turn or a subsequent turn. ${ }^{* *}$ These turns were not considered to provide verbal assistance. Acknowledgements included listening turns and discourse markers, such as yeah, ok, good. ${ }^{* * *}$ Ideas: 1 - Go to the bus stop or terminal in Montreal; 2 - Use the phone and call Montreal; 3-Refer to someone who takes the bus; 4-Use Internet; 5-Phone the terminal at the convenience store in town; 6 - Look in phone book; 7-Use 411 service. 
Scientific Research Publishing (SCIRP) is one of the largest Open Access journal publishers. It is currently publishing more than 200 open access, online, peer-reviewed journals covering a wide range of academic disciplines. SCIRP serves the worldwide academic communities and contributes to the progress and application of science with its publication.

Other selected journals from SCIRP are listed as below. Submit your manuscript to us via either submit@scirp.org or Online Submission Portal.
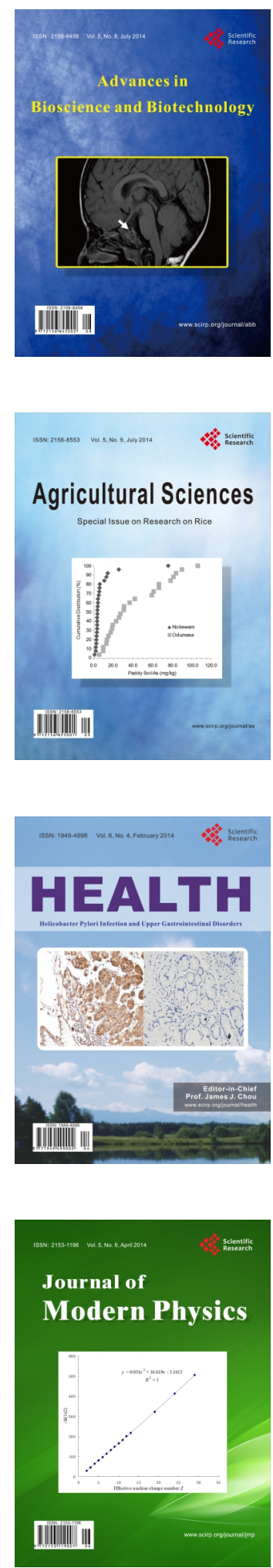
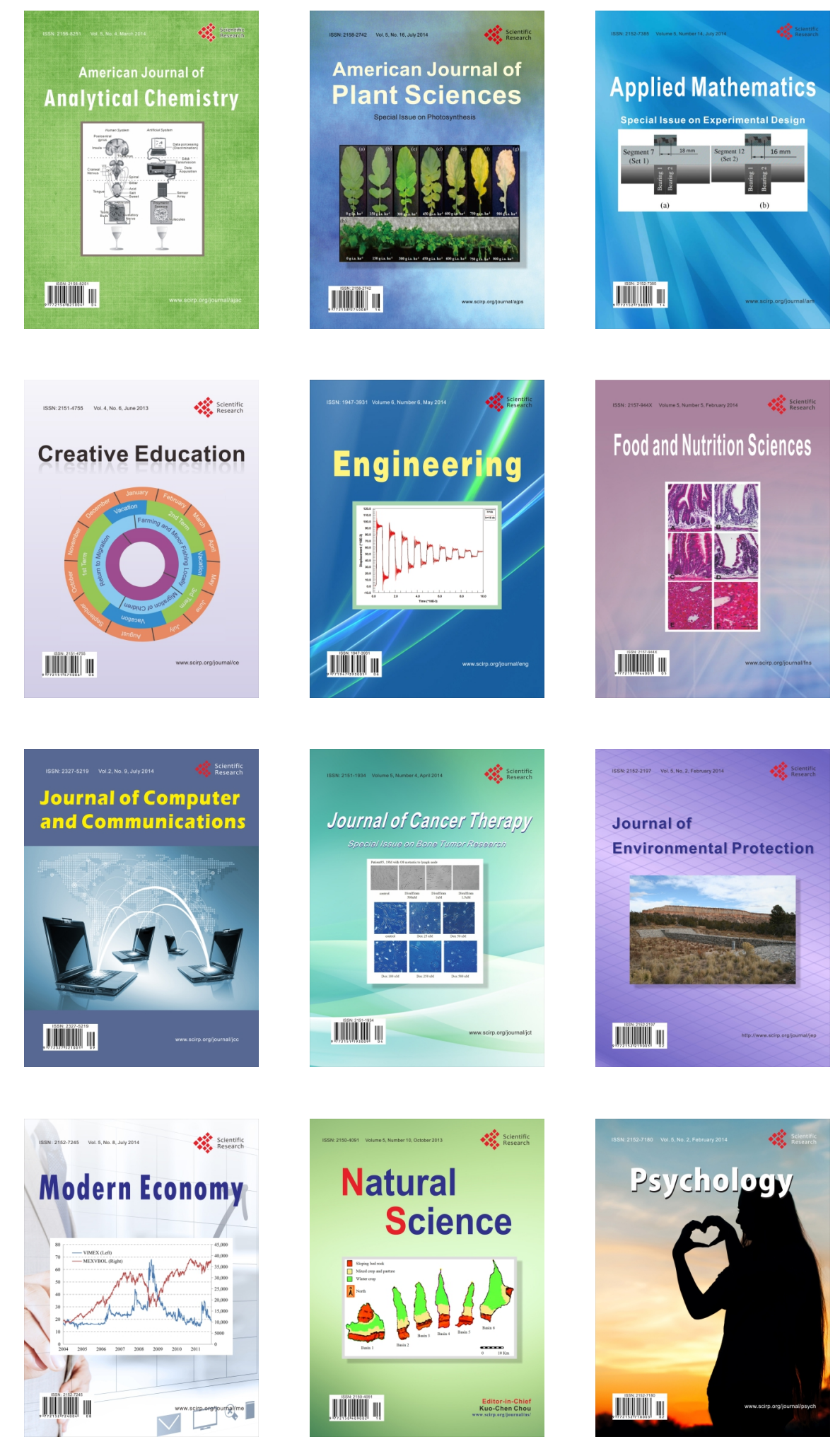